COVID-19: potential impacts on mental health. Front Immunol. 2020;11:1170.

5 Hascup ER, Hascup KN. Does SARS-CoV-2 infection cause chronic neurological complications? Geroscience. 2020;42:1083-7.

6 Rogers JP, Chesney E, Oliver D, Pollak TA, McGuire P, Fusar-Poli P, et al. Psychiatric and neuropsychiatric presentations associated with severe coronavirus infections: a systematic review and meta-analysis with comparison to the COVID-19 pandemic. Lancet Psychiatry. 2020;7:611-27.

7 Telles LE, Valenca AM, Barros AJ, da Silva AG. Domestic violence in the COVID-19 pandemic: a forensic psychiatric perspective. Braz $J$ Psychiatry. 2020 Jun 1; S1516-44462020005015211. doi: 10.1590/ 1516-4446-2020-1060. Online ahead of print.

\section{Cognitive abilities and probabilities of adherence to containment measures against the COVID-19 pandemic}

Braz J Psychiatry. 2021 Jul-Aug;43(4):447-448

doi:10.1590/1516-4446-2021-1775

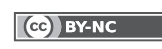

The emergence of COVID-19 has created the need for new policies based on social distancing and hygiene measures. An early study ${ }^{1}$ found that working memory (WM) capacity could predict individual differences in individuals' social distancing, although other psychological factors (e.g., depressed mood, anxious feelings, consciousness) and socioeconomic indicators were not relevant contributors in the investigation. The authors advocated that WM capacity was a good predictor of cognitive abilities, directly impacting the process of decision-making involved in adherence to containment measures.

Cognitive abilities can also be predicted by an individual's educational level, in congruence with the WM of an individual. Educational attainment is typically employed as a surrogate measure cognitive ability, and earlier studies have shown its association with a higher level of intelligence. ${ }^{1}$ Other research ${ }^{2}$ has shown that a range of demographic factors, such as income, age, educational level, and personality traits from the FiveFactor Model, could be linked to coping strategies regarding COVID-19 protective measures, and that the higher one's level of Conscientiousness, the more one is likely to adhere to protective measures. ${ }^{3}$

Due to the non-convergence of these findings, we propose investigating the impact of cognitive abilities on adherence to social distancing and hygiene measures prescribed to mitigate the impact COVID-19 and how personality traits could be used to understand this impact further. Previous studies used statistical techniques based on linear models. ${ }^{1-3}$ Therefore, direct relations were investigated, but latent probabilities of adherence were not.
Our study performed a latent profile analysis (LPA) with educational level as a covariate to pursue patterns of explanation of the heterogeneity in individual response to COVID-19 containment measures. A questionnaire was designed, with items divided into two domains: self-care during the pandemic and importance of containment measures, including items focusing on oneself and other people. Because educational level presented an impact on the profile, we then used latent transition analysis (LTA) to determine whether respondents' subgroups based on education level could be implicated in different probabilities of endorsing a given behavior related to protective measures. ${ }^{4,5}$

A two-profile model suggested a better explanation of the transition probabilities in respondents' heterogeneity. Table 1 presents the item-response probabilities.

By taking a closer look at the items, the profile class division seems to occur according to the level of Conscientiousness trait observed in each group, which would be in line with previous studies. ${ }^{1-3}$ Under those circumstances, a two-profile model is better explained according to the level of Conscientiousness when education is a covariate. Based on these findings, government and health leaders should take the educational level of population subgroups into account when proposing containment measures, considering not only which actions should be proposed but how they should be proposed so they could be more efficient. Finally, future studies should consider investigating the associations among COVID-19 protective measures and direct measures of cognitive abilities and personality traits (both normal and pathological) in a multilevel perspective.

João P.A. Lessa, Letícia M. Hofstatter, Lucas de F. Carvalho

Programa de Pós-Graduação em Psicologia, Universidade São Francisco (USF), Campinas, SP, Brazil.

Submitted Jan 27 2021, accepted Feb 13 2021, Epub Apr 052021.

\section{Disclosure}

The authors report no conflicts of interest.

How to cite this article: Lessa JPA, Hofstatter LM, Carvalho LF. Cognitive abilities and probabilities of adherence to containment measures against the COVID-19 pandemic. Braz J Psychiatry. 2021;43:447-448. http://dx.doi.org/10.1590/1516-4446-2021-1775

\section{References}

1 Xie W, Campbell S, Zhang W. Working memory capacity predicts individual differences in social-distancing compliance during the COVID-19 pandemic in the United States. Proc Natl Acad Sci U S A. 2020;117:17667-74.

2 Volk AA, Brazil KJ, Franklin-Luther P, Dane AV, Vaillancourt T. The influence of demographics and personality on COVID-19 coping in young adults. Pers Individ Dif. 2021;168:110398.

3 Carvalho LF, Pianowski G, Gonçalves AP. Personality differences and covid-19: are extroversion and conscientiousness personality 
Table 1 Transition probabilities in respondent heterogeneity, controlled by educational level

\begin{tabular}{|c|c|c|c|c|c|c|c|c|}
\hline \multirow[b]{3}{*}{ Item } & \multicolumn{8}{|c|}{ Response categories } \\
\hline & \multicolumn{2}{|c|}{ DT } & \multicolumn{2}{|c|}{$\mathrm{D}$} & \multicolumn{2}{|c|}{$\mathrm{C}$} & \multicolumn{2}{|c|}{ CT } \\
\hline & Low & High & Low & High & Low & High & Low & High \\
\hline $\begin{array}{l}\text { I am more concerned with getting COVID-19 than concerned with } \\
\text { the possibility of others getting it. }\end{array}$ & 0.46 & 0.42 & 0.41 & 0.54 & 0.01 & 0.00 & 0.12 & 0.04 \\
\hline $\begin{array}{l}\text { I'm more concerned with the people around me getting COVID-19 } \\
\text { than myself** }\end{array}$ & 0.08 & 0.08 & 0.39 & 0.63 & 0.02 & 0.02 & 0.51 & 0.27 \\
\hline Much of what is said about COVID-19 is fake. & 0.69 & 0.61 & 0.23 & 0.37 & 0.00 & 0.00 & 0.09 & 0.02 \\
\hline People are exaggerating the measures taken against COVID-19. & 0.69 & 0.62 & 0.25 & 0.35 & 0.01 & 0.00 & 0.05 & 0.03 \\
\hline $\begin{array}{l}\text { I didn't change my routine because of COVID-19, since where I live, } \\
\text { it doesn't exist.* }\end{array}$ & 0.02 & 0.06 & 0.18 & 0.47 & 0.01 & 0.03 & 0.79 & 0.44 \\
\hline $\begin{array}{l}\text { I have a hard time following the recommendations against COVID- } \\
19 \text { because they harm me at work.* }\end{array}$ & 0.57 & 0.63 & 0.22 & 0.30 & 0.01 & 0.00 & 0.20 & 0.06 \\
\hline $\begin{array}{l}\text { Following the recommendations against COVID-19 is a problem, as } \\
\text { I need to help one or more people outside my home.* }\end{array}$ & 0.03 & 0.05 & 0.12 & 0.19 & 0.10 & 0.50 & 0.74 & 0.26 \\
\hline $\begin{array}{l}\text { It is tough for me to follow the recommendations against COVID-19, } \\
\text { as I have a disease, and I need to treat myself outside my home.* }\end{array}$ & 0.00 & 0.04 & 0.02 & 0.16 & 0.05 & 0.41 & 0.94 & 0.39 \\
\hline $\begin{array}{l}\text { I've been losing (or making less) money since the COVID-19 } \\
\text { pandemic.* }\end{array}$ & 0.00 & 0.03 & 0.02 & 0.17 & 0.13 & 0.59 & 0.84 & 0.22 \\
\hline $\begin{array}{l}\text { I have suffered a lot from not meeting with my family and friends } \\
\text { because of the COVID-19 pandemic.* }\end{array}$ & 0.01 & 0.11 & 0.13 & 0.23 & 0.10 & 0.45 & 0.76 & 0.22 \\
\hline $\begin{array}{l}\text { I am very concerned about people in my family or friends who are at } \\
\text { risk for COVID-19.* }\end{array}$ & 0.01 & 0.03 & 0.00 & 0.13 & 0.05 & 0.34 & 0.94 & 0.50 \\
\hline I am very concerned because I am a risk group for COVID- 19 . & 0.61 & 0.78 & 0.14 & 0.13 & 0.09 & 0.06 & 0.15 & 0.03 \\
\hline
\end{tabular}

$\mathrm{C}=$ agree; $\mathrm{CT}$ = agree completely; $\mathrm{D}=$ disagree; DT = disagree completely; High = profile with a higher level of consciousness; Low = profile with a lower level of consciousness).

Bold type denotes significant differences among transition probabilities.

* Items impacted by educational level.

traits associated with engagement with containment measures? Trends Psychiatry Psychother. 2020;42:179-84.

4 Bray BC, Smith RA, Piper ME, Roberts LJ, Baker TB. Transitions in smokers' social networks after quit attempts: a latent transition analysis. Nicotine Tob Res. 2016;18:2243-51.

5 Collins LM, Lanza ST. Latent class and latent transition analysis: with applications in the social, behavioral and health sciences. New York: Wiley \& Sons; 2010.

\section{Which is the best way of using nitrous oxide for treatment and research in neuropsychiatry?}

Braz J Psychiatry. 2021 Jul-Aug;43(4):448-449 doi:10.1590/1516-4446-2021-1879

(cc) BY-NC

I welcome the excellent paper by Guimarães et al. ${ }^{1}$ which extends research on nitrous oxide $\left(\mathrm{N}_{2} \mathrm{O}\right)$ in neuropsychiatry - a neglected field, since our initial work in 1982 and then $1985^{2}$ indicating that low, anxiolytic, and non-anaesthetic doses of $\mathrm{N}_{2} \mathrm{O}$ ameliorate depression. ${ }^{3}$ Research has demonstrated that $\mathrm{N}_{2} \mathrm{O}$, at subanaesthetic concentrations acts on opioid receptors. ${ }^{2,3}$ We therefore concluded that the antidepressant activity of $\mathrm{N}_{2} \mathrm{O}$ occurred via opioid activity. ${ }^{2,3}$

Interestingly, this latest work ${ }^{1}$ confirms our findings that the antidepressant action of $\mathrm{N}_{2} \mathrm{O}$ occurred immediately and endured after gas administration. ${ }^{2,3}$ It also supports our unpublished observation that the gas could be used as an adjuvant to routine antidepressant medication. ${ }^{2,3}$

Like Nagele's group, ${ }^{1}$ Guimarães et al. ${ }^{1}$ believe that $\mathrm{N}_{2} \mathrm{O}$ and ketamine are antidepressant mainly via antagonism of the $\mathrm{N}$-methyl-D-aspartate receptor (NMDAr). However, they provide two key references disputing NMDAr involvement. ${ }^{1}$ One showed that naloxone blocks the antidepressant action of ketamine, and the other that NMDAr antagonists (like memantine) are not antidepressant. ${ }^{1}$ These references and our work ${ }^{2,3}$ indicate that opioid receptors are more likely to be responsible for the antidepressant action of $\mathrm{N}_{2} \mathrm{O}$ and ketamine. Indeed, NMDAr blockade occurs only at $\mathrm{N}_{2} \mathrm{O}$ concentrations 